\title{
The sample size debate: response to Norman Blaikie
}

\author{
Julius Sim, ${ }^{1}$ Benjamin Saunders, ${ }^{1}$ Jackie Waterfield, ${ }^{2}$ Tom Kingstone ${ }^{1}$ \\ ${ }^{1}$ Institute for Primary Care and Health Sciences, Keele University, Staffordshire ST5 5BG, \\ UK
}

${ }^{2}$ School of Health Sciences, Queen Margaret University, Edinburgh EH 216UU, UK

* corresponding author, j.sim@keele.ac.uk

\begin{abstract}
In his detailed response to our paper on sample size in qualitative research, Norman Blaikie raises important issues concerning conceptual definitions and taxonomy. In particular, he points out the problems associated with a loose, generic application of adjectives such as 'qualitative' or 'inductive.' We endorse this concern, though we suggest that in some specific contexts a broad categorization may be more appropriate than a more nuanced distinction - provided that it is clear in which sense the terms are employed. However, other concepts, such as saturation, do not lend themselves to generic use, and require a more detailed conceptualization. Blaikie’s analysis also makes it clear that meaningful discussion of sample size in qualitative research cannot occur with reference to an undifferentiated conception of the nature of qualitative research; clear distinctions need to be made within this approach in terms of methodology, ontological and epistemological assumptions, and broader research paradigms.
\end{abstract}

Keywords: sampling, sample size, qualitative research 
In his response (Blaikie, 2018) to our paper (Sim et al, 2018), Norman Blaikie raises a number of important issues that are relevant not only to the issue of sample size but also to how we think about social research more broadly. Much of his discussion centres on issues of definition or taxonomy, and our rejoinder will take these as its primary focus.

We agree that, as a term that strictly applies at the level of data, the use of 'qualitative' as a form of synecdoche to denote a broader research approach, or as a form of metonymy to describe researchers who carry out such research, is in some respects problematic. It obscures the interplay between design, data collection, data analysis and theorizing, and thereby tends to homogenize research approaches that, whilst lying within a particular broad tradition, are different in important ways in terms of both their methodology and their underlying philosophical assumptions. Furthermore, classifying research as either qualitative or quantitative tends to reinforce the view that these are irreconcilable polar opposites. In our view, a classification of research on the basis of the research question, as being either 'exploratory’, ‘descriptive’ or ‘explanatory’ (Sim and Wright, 2000; Robson, 2002), provides a clearer and more discriminating understanding of different approaches to research.

However, terminology needs to be matched to the context in which it is used. Provided that it does not give rise to serious misconceptions, a somewhat crude classification (such as qualitative versus quantitative) may sometimes be more helpful in the circumstances and for the audience concerned than a subtler one (such as exploratory versus descriptive versus explanatory), particularly where the aim is to encourage a broad audience of researchers to engage with these issues and to think more carefully about the implications for their own research. In a similar way, our characterization of grounded theory as broadly inductive (Sim et al, 2018) is, we believe, probably sufficient in terms of framing the discussion on sample size, even though a full account of the process of analysis in grounded theory would need to consider an abductive as well as an inductive logic, particularly if wishing to describe different phases of the analysis or to contrast the different approaches within grounded theory (Charmaz 2009; Reichertz, 2007). We would not wish, however, to suggest that an inductive logic 'incorporates' an abductive logic - rather, that each of these shares a broad conception of the relationship between data and theory, implicit in Blaikie's definition of these terms.

The issue of themes is another case in point. In defining a theme, Braun and Clarke (2006 p. 82) state that it 'captures something important about the data in relation to the research question, and represents some level of patterned response or meaning within the data set' 
(original emphasis). As these authors indicate, thematic analysis, defined in this broad manner, may be associated with a variety of modes of analysis, and 'theme' may therefore be used as quite a generic term. However, Braun and Clarke (2006) proceed to describe a particular approach to thematic analysis that has distinct characteristics, and differs in certain important respects from the forms of thematic analysis described by Boyatzis (1998) and Guest, MacQueen and Namey (2012). The specificity with which thematic analysis needs to be defined is, again, related to the context of its use. ${ }^{1}$

In contrast to the above examples, however, is the concept of saturation. Blaikie (2018) gives a clear description of what he understands by saturation in the context of sampling for typological analysis. Such specificity is crucial, as the different ways in which saturation is conceptualized have important implications for its use (Saunders et al, 2017); accordingly, the generic use of this term has little to recommend it. ${ }^{2}$

Another key message to be drawn from Blaikie’s (2018) discussion is that questions of sample size - and those relating to other aspects of methodology - cannot be settled by reference to an undifferentiated conception of what constitutes 'qualitative' research. ${ }^{3}$ Within this tradition of research, there are important distinctions in terms of methodology, ontological and epistemological assumptions, and broader research paradigms. ${ }^{4}$ As we have tried to indicate in our paper (Sim et al., 2018), choices regarding sample size must take account of, for example, whether a phenomenological or an ethnographic methodology is employed, or whether analysis is based on the principles of interpretive phenomenological analysis (Smith, Flowers \& Larkin, 2009) or qualitative content analysis (Schreier, 2014).

Not only is 'qualitative' research often viewed in undifferentiated terms, but it is also prone to certain unwarranted conjunctions - for example, that it is necessarily idiographic and averse to any form of generalization, or that it must be concerned with an interpretive understanding, or that if it is indeed taking an interpretive stance, focusing on subjective meanings, the phenomenon that it studies cannot be a natural kind but must in some sense be socially constructed, or that hypotheses are necessarily incompatible with this type of research. To take the last two of these claims, a study that seeks, for example, to gain an interpretive understanding of the subjective experience of living with diabetes is not thereby committed to regarding this condition as a social construct rather than a 'real' disease. Equally, as Blaikie (2018) suggests, hypotheses may feature in 'qualitative’ research. When they do, however, it is likely to be in a very different way from their role in studies where 
statistical hypothesis-testing is the driving force behind design and analysis (Mead, 1988). Thus, the process of constant comparison during coding and category formation within grounded theory can be viewed in terms of testing certain emergent hypotheses (Glaser \& Strauss, 1967), but in a radically different way from the testing of a priori hypotheses in research based on the hypotheticodeductive model.

In closing, we reiterate our agreement with Blaikie regarding the problems of considering 'qualitative' research in a manner that is in one sense very broad, but that also assumes narrow associations with specific logics of inquiry. However, whilst clearly important in the sample size debate, this issue opens up a much wider discussion. We naturally welcome this discussion, but would re-emphasize the context in which terminology is used, and the need to consider whether or not a particular term lends itself to being employed generically. This is not to suggest that misconceptions in the use of terms such as 'qualitative' should go unchallenged; but perhaps we should pick our battles one at a time. For the specific purposes of articulating the primary argument in our paper - that defining sample size a priori in research that 'adopts a logic of inquiry in which knowledge evolves as an outcome of an iterative process' (Blaikie, 2018) is in essence illogical - we would suggest that the term 'qualitative', and a somewhat simplified distinction between 'inductive' and 'deductive', are perhaps appropriate here. At the same time, we believe that discussing sample size in relation to a loosely defined conception of saturation is unhelpful and misguided. As these debates progress, and, optimistically, some of the more problematic assumptions we identified concerning sample size become less prevalent, perhaps then we can begin to challenge thinking around this terminology more fully. So, picking up on Blaikie’s (2018) closing sentence, whilst we agree that caution must be taken in the use of 'qualitative' in sample size discussions, perhaps we need not go so far as to leave it out entirely. 


\footnotetext{
${ }^{1}$ DeSantis and Ugarriza (2000 p. 369) express concern at the 'varied and imprecise use of the term theme as it is applied from one qualitative research method to another.' The imprecision they refer to is indeed problematic, but whilst we might expect consistency in the use of 'theme' within a particular method, variation in use across different methods may simply reflect underlying differences in such methods.

${ }^{2}$ Perhaps more pernicious is where crude terminology or classifications are used in a misleading way. Describing 'quantitative' research as positivist, often as a mark of opprobrium, overlooks the fact that such research need not embody all of the classic assumptions of positivism - in particular, its hostility to theoretical entities (Hacking, 1983).

${ }^{3}$ We follow Blaikie's (2018) use of inverted commas to signal reservations as to the use of this term. We would also note, however, that this might well be an occasion where the broad use of the terms 'qualitative' (or 'quantitative') is not out of place.

${ }^{4}$ Blaikie and Priest (2017) provide detailed discussion of neo-positive, interpretive and critical realist paradigms, arguing that whilst such paradigms are unavoidable in social research, exclusive loyalty to just one paradigm is unnecessary.
}

\section{References}

Blaikie, N. (2018). Confounding issues related to determining sample size in qualitative research. International Journal of Social Research Methodology, XX, xxx-xxx.

Blaikie, N. and Priest, J. (2017). Social research: Paradigms in action. Cambridge: Polity Press.

Boyatzis, R.E. (1998). Transforming qualitative information: Thematic analysis and code development. Thousand Oaks: Sage.

Braun, V. \& Clarke, V. (2006) Using thematic analysis in psychology. Qualitative Research in Psychology, 3, 77-101.

Charmaz, K. (2009). Shifting the grounds: constructivist grounded theory methods. In J.M. Morse, P.N. Stern, J. Corbin, B. Bowers, K. Charmaz \& A.E. Clarke (Eds.) Developing grounded theory: The second generation (pp. 127-154). Walnut Creek, CA: Left Coast Press.

DeSantis, L., \& Ugarriza, D.N. (2000). The concept of theme as used in qualitative nursing research. Western Journal of Nursing Research, 22, 351-372.

Glaser, B. G. \& Strauss, A. L. (1967). The discovery of grounded theory: Strategies for qualitative research. Chicago: Aldine. 
Guest, G., MacQueen, K.M. \& Namey, E.E. (2012). Applied thematic analysis. Thousand Oaks, CA: Sage.

Hacking, I. (1983). Representing and intervening: Introductory topics in the philosophy of natural science. Cambridge: Cambridge University Press.

Mead, R. (1988). The design of experiments: Statistical principles for practical application. Cambridge: Cambridge University Press.

Reichertz, J. (2007). Abduction: the logic of discovery in grounded theory. In A. Bryant \& C. Charmaz (Eds) The SAGE handbook of grounded theory (pp.214-228). Thousand Oaks, CA: Sage.

Robson, C. (2002). Real world research: A resource for social scientists and practitioner-researchers (2nd ed). Oxford: Blackwell.

Saunders, B., Sim, J., Kingstone, T., Baker, S., Waterfield, J., Bartlam, B., Burroughs, H., \& Jinks, C. (2017). Saturation in qualitative research: exploring its conceptualization and operationalization. Quality and Quantity, doi: 10.1007/s11135-017-0574-8

Schreier, M. (2014). Qualitative content analysis. In U. Flick (Ed) The Sage handbook of qualitative data analysis (pp. 170-183). London: Sage.

Sim, J., Saunders, B., Waterfield, J. and Kingstone, T. (2018). Can sample size in qualitative research be determined a priori? International Journal of Social Research Methodology, $\mathrm{XX}$, xxx-xx.

Sim, J, \& Wright, C. (2000). Research in health care: Concepts designs and methods. Cheltenham: Stanley Thornes.

Smith, J.A., Flowers, P., \& Larkin, M. (2009). Interpretative phenomenological analysis: Theory, method and research. London: Sage. 